\title{
Fetal origins of adult disease: epidemiology and mechanisms
}

\author{
C D Byrne, D I Phillips
}

\begin{abstract}
The past 10 years have provided unequivocal evidence that there are associations between birth size measures and future development of adult diseases, such as type 2 diabetes and coronary artery disease. Despite initial concern that bias or residual confounding in the analyses had produced these rather bizarre associations, the findings have now been reproduced in different cohorts by independent investigators from many parts of the world. The challenge for the next decade must be to discover the cellular and molecular mechanisms giving rise to these associations. If this aim is accomplished, it might be possible to devise strategies to reduce the impact of these disabling, chronic, and expensive diseases. The purpose of this review is to describe some of the relevant, important, and more recent epidemiological studies, and also to discuss potential mechanisms underpinning the associations.

(F Clin Pathol 2000;53:822-828)
\end{abstract}

Keywords: atherosclerotic vascular disease; type 2 diabetes; birth weight

The notion that chronic adult diseases, such as coronary artery disease, might be influenced by events occurring in the fetus was proposed by Barker and colleagues approximately 10 years ago. ${ }^{1}$ Despite criticism of the validity of the initial observations, the associations between parameters of early growth and adult disease have now been reproduced by many investigators from different parts of the world. ${ }^{2-4}$ However, a unifying hypothesis to explain the associations between abnormal fetal growth and subsequent adult disease, often developing many years later, remains elusive. Barker has proposed that these associations arise as a result of the phenomenon of "programming". Programming describes persisting changes in structure and function caused by environmental stimuli during crucial periods of early development. It is proposed that an inadequate fetal nutrient supply sufficient to reduce fetal growth results in long term changes in physiological and metabolic processes, which predispose to atherosclerotic vascular disease and/or type 2 diabetes. However, other explanations, including the operation of genetic factors and programming of certain endocrine axes, have also been put forward to explain the epidemiological associations. ${ }^{5}$ This review describes some of the important, relevant, and more recent epidemiological associations and also discusses mechanisms that might explain these associations.

\section{Introduction}

Death rates in babies in the 1900s showed that the usual cause of certified death was low birth weight, and both men and women who were small at birth were at increased risk of coronary artery disease and stroke. Death rates differed greatly across the country, being highest in northern industrial towns and poorer rural towns in the north and west. Interestingly, geographical patterns of variation in death rates from coronary artery disease were remarkably similar to death rates in newborn babies. This striking similarity suggested that the pattern might be attributable to similar factors contributing to deaths in newborns and deaths in adults from coronary artery disease. The proposal that events in childhood influenced adult disease was not new. However, the unique feature of the hypothesis proposed by Barker was the suggestion that intrauterine events influenced adult disease.

Epidemiological associations linking fetal growth and adult disease

BIRTH SIZE MEASURES AND ADULT DISEASE

The epidemiological evidence that pointed to the importance of low birth weight in the aetiology of coronary heart disease was based on the long term follow up of men and women whose measurements at birth had been recorded routinely. Among 10141 men born in Hertfordshire between 1911 and 1930, death rates from coronary artery disease were two times lower in those at the upper end of the distributions of birth weight and weight at 1 year of age than in those at the lower end. ${ }^{6}$ Table 1 shows the death rates from coronary artery disease among 16000 men and women in Hertfordshire according to birth weight.

A study in Sheffield where detailed obstetric records are available showed that it was men who were small at birth because they were growth retarded, rather than premature, who were at increased risk. ${ }^{7}$ In both populations, low birth weight was associated with an

Table 1 Death rates from coronary artery disease among 16 000 men and women born in Hertfordshire between 1911 and 1930 according to birth weight

\begin{tabular}{lcc}
\hline Birth weight (lbs) & $\begin{array}{l}\text { Standardised } \\
\text { mortality ratio }\end{array}$ & Deaths $(n)$ \\
\hline$\leqslant 5.5$ & 100 & 57 \\
$5.6-6.5$ & 81 & 137 \\
$6.6-7.5$ & 80 & 298 \\
$7.6-8.5$ & 74 & 289 \\
$8.6-9.5$ & 55 & 103 \\
$>9.5$ & 65 & 57 \\
All & 74 & 941 \\
\hline
\end{tabular}


Table 2 Prevalence of the metabolic syndrome in men aged 64 years according to birth weight

\begin{tabular}{lcll}
\hline Birth weight $(l b)$ & No of men & $\begin{array}{l}\text { Percent with metabolic } \\
\text { syndrome }\end{array}$ & Odds ratio \\
\hline$<5.5$ & 20 & 30 & $18(2.6$ to 118$)$ \\
$5.6-6.5$ & 54 & 19 & $8.4(1.5$ to 49$)$ \\
$6.6-7.5$ & 114 & 17 & $8.5(1.5$ to 46$)$ \\
$7.6-8.5$ & 123 & 12 & $4.9(0.9$ to 27$)$ \\
$8.6-9.5$ & 64 & 6 & $2.2(0.3$ to 14$)$ \\
$>9.5$ & 32 & 6 & 1.0 \\
Total & 407 & 14 & p for trend $<0.001$ \\
\hline
\end{tabular}

increased risk of stroke. ${ }^{8}$ The association between low birth weight and coronary artery disease has subsequently been confirmed in studies of men in Uppsala, Sweden ${ }^{4}$; Helsinki, Finland ${ }^{9}$; and Caerphilly, South Wales ${ }^{10}$; and among 80000 women in the American nurses study, where there was a similar twofold decrease in relative risk for non-fatal coronary heart disease across the range of birth weights. ${ }^{2}$ Similarly in India, among South Indian men and women, the prevalence of coronary artery disease fell from $18 \%$ in those who weighed $2500 \mathrm{~g}$ at birth to $4 \%$ in those who weighed $3200 \mathrm{~g}$ at birth. ${ }^{3}$

The Hertfordshire study and many of the other studies throughout the world only have data on the weight of the baby at birth. Clearly, birth weight is only a summary measure of growth and development of the fetus in utero. Where data are available on other anthropometric measurements at birth, including body length and head circumference, they show that suboptimal fetal growth, as indicated by thinness at birth (that is, a low ponderal index: birth weight/length ${ }^{3}$ ) or stunting, predict atherosclerotic vascular disease in later life. ${ }^{9}$

The associations between birth size and cardiovascular disease are parallelled by associations between early growth and many risk factors for cardiovascular disease, in particular type 2 diabetes and hypertension. In Hertfordshire, the prevalence of type 2 diabetes or its precursor, glucose intolerance, fell from $40 \%$ among those who weighed $\leqslant 5.5 \mathrm{lb}$ at birth to $14 \%$ in those who weighed $\geqslant 9.5 .{ }^{11}$ To date, 70 studies throughout the world have replicated the association between birth size parameters and hypertension, and 30 studies have shown an association between these parameters and glucose intolerance. Taken together, these studies have involved approximately 400000 individuals (CM Law, 1999, personal communication). ${ }^{12}{ }^{13}$ Type 2 diabetes and hypertension frequently occur together in the same patients and this combination, which is also associated with other disorders such as dyslipidaemia, central obesity, and insulin resistance, is known as the metabolic syndrome, which strongly predisposes to atherosclerotic vascular disease. Low birth weight is strongly associated with the metabolic syndrome, and the prevalence of this syndrome fell from $30 \%$ among men in Hertfordshire who were $\leqslant 5.5 \mathrm{lb}$ at birth, to $6 \%$ in those who weighed $\geqslant 9.5 \mathrm{lb}$ (table 2$).{ }^{14}$

Although obesity, and in particular central obesity, predispose to the development of the metabolic syndrome, it seems that the effects of low birth weight and adult obesity are additive. The highest risk of developing the metabolic syndrome is among men and women who were small at birth but who become obese in adult life. Because the metabolic syndrome is characterised by insulin resistance, this suggested that low birth weight might be associated with insulin resistance. Insulin resistance was measured using a short insulin tolerance test in a sample of men and women in the Preston study. The results suggested that men and women who were thin at birth, as indicated by a low ponderal index, were insulin resistant in adult life. ${ }^{15}$ The association was independent of current body mass index. The relation between reduced fetal growth and insulin resistance has now been confirmed by a variety of techniques including the euglycaemic clamp and the intravenous glucose tolerance test with minimal modelling. ${ }^{16-19}$ Taken together with the data on the relation between birth weight and the prevalence of the metabolic syndrome, these findings suggest that insulin resistance may originate through impaired development in fetal life, and might play an important part in mediating the link between low birth weight and cardiovascular disease. ${ }^{20}$

IN CHILDHOOD AND EARLY ADULTHOOD, DO RELATIONSHIPS EXIST BETWEEN RISK FACTORS FOR CHRONIC DISEASE AND BIRTH SIZE PARAMETERS?

The existence of associations between birth weight and adult disease does not prove that a there is a causal relation between parameters of early development and future adult disease. In an attempt to strengthen the body of evidence supporting a causal link, the relation between size at birth (birth weight, thinness at birth) and concentrations of plasma glucose and serum insulin has been examined in children, and the associations compared with those occurring with measures of current childhood size. A school based survey of 10 to 11 year old UK children was undertaken (response rate, $64 \%$ ), with measurements made after an overnight fast. One group of children $(n=591)$ was studied fasting, whereas the other $(n=547)$ was studied 30 minutes after a standard oral glucose load $(1.75 \mathrm{~g} / \mathrm{kg})$. Birth weight was assessed by maternal recall and thinness at birth using birth records. In this study, neither fasting nor post-load glucose concentrations showed any consistent relation with birth weight or ponderal index at birth. However, after adjustment for childhood height and ponderal index, both fasting and post-load insulin values fell with increasing birth weight. These investigators showed that for each $\mathrm{kg}$ increase in birth weight, fasting insulin fell by $16.9 \%$ and post-load insulin by $11.6 \%$, although the proportional change in insulin value for a $1 \mathrm{SD}$ increase in childhood ponderal index was much greater than that for birth weight $(27.2 \%$ and $-8.8 \%$, respectively, for fasting insulin). The authors concluded that low birth weight is not related to glucose intolerance at 10-11 years. They suggested that reduced birth weight might be related to the early development of insulin resistance, but in contemporary 
children, obesity is a stronger determinant of insulin concentration and insulin resistance than size at birth. ${ }^{21}$

It was shown in a cohort of 7 year old children in Salisbury, UK, that thinness at birth is associated with increased 30 minute glucose concentrations. To discover whether thinness at birth is associated with reduced glucose tolerance in children, 250 children aged 7 years underwent an abbreviated oral glucose tolerance test. Children who were thin at birth, as measured by a low ponderal index, had higher plasma glucose concentrations. The plasma glucose concentration 30 minutes after a glucose load rose by $0.07 \mathrm{mmol} /$ litre for every unit $\left(\mathrm{kg} / \mathrm{m}^{3}\right)$ fall in ponderal index. Children in the lowest quarter of the distribution of ponderal index $\left(\leqslant 23 \mathrm{~kg} / \mathrm{m}^{3}\right)$ had a mean 30 minute plasma glucose concentration of $8.49 \mathrm{mmol} /$ litre compared with a mean of 7.97 $\mathrm{mmol} /$ litre for those in the highest quarter $\left(>27.5 \mathrm{~kg} / \mathrm{m}^{3}\right)$. These associations were independent of duration of gestation, sex, social class, or the child's current weight. Thus, this finding is not completely in keeping with the observation in 11 year old children discussed above. $^{22}$

Yajnik and colleagues studied 4 year old Indian children, to determine whether low birth weight is associated with reduced glucose tolerance in Indian children. ${ }^{23}$ Glucose tolerance tests were carried out on 379 children aged 4 years, whose birth weights were recorded, in Pune, India. Among 201 children who had been looked after on the routine postnatal wards at birth, those with lower birth weights had higher plasma glucose and insulin concentrations 30 minutes after an oral glucose load, independent of their current size. Mean glucose and insulin concentrations were $8.1 \mathrm{mmol} /$ litre and $321 \mathrm{pmol} /$ litre, respectively, in children whose birth weight had been $2400 \mathrm{~g}$ or less, compared with $7.5 \mathrm{mmol} /$ litre and $289 \mathrm{pmol} /$ litre, respectively, in those who weighted more than $3000 \mathrm{~g}$. Among 178 children who had been looked after in the special care baby unit, those with lower birth weights also had higher plasma insulin concentrations at 30 minutes, but there were no trends with plasma glucose. These findings suggested that Indian children with reduced intrauterine growth might have altered glucose homeostasis.

To determine relations between schoolchildren's blood pressure, glycated haemoglobin value, and cholesterol concentration and their anthropometry, socioeconomic status, and birth measurements, Forrester and colleagues undertook a retrospective cohort study in 27 schools closest to the University Hospital, Kingston, Jamaica. Two thousand three hundred and thirty seven children aged $6-16$ years were recruited, and their birth records were recovered. Of these individuals, 1610 had suitable records, 659 had records including birth length, and 610 of these were prepubertal. Systolic blood pressure was inversely related to their birth weight and directly related to their current weight. Glycated haemoglobin was higher in children with thicker triceps skinfolds and who had been shorter at birth. Serum cholesterol was inversely related to current height and was directly related to triceps skinfold thickness and higher socioeconomic status. Thus, blood pressure was inversely related to birth weight and directly related to current weight. Glycaemic control and serum cholesterol were related to short length at birth, height deficit in childhood, and childhood obesity. ${ }^{24}$

Thus, parameters of childhood growth and obesity seem to be important determinants of cardiovascular risk factors in children. Given the uncertain relevance of modest changes in these measured parameters in childhood, predisposing to either type 2 diabetes and/or atherosclerotic vascular disease in adulthood, the importance of these studies is unknown.

POTENTIAL CONFOUNDING FACTORS

It is often argued that a relation between altered patterns of development occurring in the fetus and future development of adult disease is confounded by other factors. The same factor(s) that causes reduced fetal growth and development might also predispose to adult disease. Individuals whose growth was impaired during early development might continue to be exposed to the same adverse environment in childhood and early adulthood, which might cause adult disease. Thus, these later life events could be interpreted as being the result of programming. However, in studies in which data were available on lifestyle factors, including smoking, employment, alcohol consumption, and exercise, these lifestyle factors had little effect on the independent relation between birth weight and coronary artery disease.

\section{Potential mechanisms linking fetal growth and adult disease}

The molecular and cellular mechanisms that could explain the link between reduced fetal growth and the metabolic syndrome in adult life are not understood but are currently under intensive investigation.

DOES GENETIC VARIATION MEDIATE A LINK BETWEEN REDUCED BIRTH SIZE AND ADULT DISEASE?

It is possible that there is a genetic basis underpinning the link between fetal growth and the metabolic syndrome. It is known that insulin has a central role in fetal growth, ensuring that growth rates are commensurate with the nutrient supply. Experimental manipulations that reduce insulin secretion in utero also reduce fetal growth. ${ }^{25}$ Hence, any gene reducing insulin secretion would also be expected to lower birth weight and predispose to diabetes in adult life. Recently, it has shown that diabetes caused by the rare mutation of the pancreatic glucose sensing gene, glucokinase, which is a regulator of insulin secretion, is associated with a $500 \mathrm{~g}$ birth weight reduction. ${ }^{26}$ Furthermore, as well as genes modulating insulin secretion, genes determining insulin resistance would also impair fetal growth. This phenomenon has been demonstrated in transgenic mice lacking 
key intermediates in the insulin receptor signalling mechanism. ${ }^{27} \mathrm{McCance}$ et al have taken this idea further by suggesting that genes promoting fetal insulin resistance would increase survival of a fetus exposed to undernutrition in utero. In conditions of undernutrition, a genotype conferring insulin resistance would be preferentially selected for during evolution because this genotype would increase survival among small babies, who would otherwise have a high perinatal mortality. This phenomenon has been referred to as "the surviving small baby hypothesis". ${ }^{28}$ Dungar has studied common allelic variation at the variable number of tandem repeats (VNTR) locus in the insulin promoter region of the insulin gene. In a prospective study of 758 children born in Avon, the III/III genotype, which has a prevalence of about $9 \%$, was found to be linked with a $200 \mathrm{~g}$ increase in birth weight and larger body size at birth. ${ }^{5}$ Other studies have previously shown associations between this genotype and insulin resistance or type 2 diabetes. On the basis of this finding, the authors suggested that this gene, which increased birth weight, might enhance perinatal survival and perhaps paradoxically increase susceptibility to type 2 diabetes. However, despite this association, it is difficult to rationalise how this gene might explain an association between low birth weight and type 2 diabetes. Indeed, a recent analysis suggested that the influence of this polymorphism was much smaller than the stronger birth size effect in the Hertfordshire cohort. $^{29}$

Although genes might contribute to the association between birth size and diabetes, several sources of evidence suggest that it is the maternal environment rather than genetic factors that is the dominant influence on birth size. The strong influence of the mother is demonstrated by half sibling studies showing a stronger correlation between the birth weights of half siblings sharing the same mother $(r=0.58)$ than among half siblings who share a father $(r=0.1) \cdot{ }^{30}$ In an analysis of the familial aggregation of birth weight, Penrose concluded that $62 \%$ of the variation in birth weight was the result of the intrauterine environment, 20\% resulted from maternal genes, and $18 \%$ from fetal genes. ${ }^{31}$ The importance of the maternal environment is also supported by animal cross breeding experiments and by embryo transfer experiments; a fetus transferred to a larger uterus will attain a larger birth size. ${ }^{32}$ Recent important evidence that the diabetogenic effect of small birth size is not genetic has come from an analysis of the relation between birth size and diabetes in the Danish Twin Registry. Poulsen and colleagues found 14 pairs of monozygous twins discordant for type 2 diabetes. The twins with diabetes had significantly lower birth weights than the nondiabetic twins (2571 $v 2841 \mathrm{~g}, \mathrm{p}<0.0001)$. Because of the genetic identity of monozygous twins, this finding suggests that the association between low birth weight and type 2 diabetes is independent of genetic factors. ${ }^{33}$
DOES FETAL MALNUTRITION MEDIATE A LINK BETWEEN REDUCED FETAL GROWTH AND ADULT DISEASE?

Poor maternal nutrition during crucial periods of fetal development might not only impair fetal growth but might permanently affect the structure and physiology of several organs and tissues. For example, a reduced nutrient supply to the fetal guinea pig induced by either unilateral uterine artery ligation or a low protein maternal diet during gestation in rats causes a lifelong increase in blood pressure in the offspring. ${ }^{3435}$ These results represent examples of programming where the stimulus applied during development has resulted in lifelong effects. The data from these experiments led to the hypothesis that an association between reduced fetal growth and diabetes in adult life occurred because of fetal undernutrition. This hypothesis is supported by a follow up study of babies born in the "Dutch hunger winter" of 1944. This study of men and women, aged 50 years, who were born around the time of the Dutch famine shows that undernutrition particularly during the later stages of gestation was associated with reduced glucose tolerance in middle age, and this effect was independent of any influence of adult obesity. ${ }^{36}$

However, to date, it is uncertain whether maternal malnutrition is uniquely responsible for an association between birth weight and subsequent adult disease. To investigate the relation between decreased maternal food intake and risk factors for coronary heart disease in adult life, a cross sectional study of 169 subjects exposed to malnutrition in utero (intrauterine group) during the siege of Leningrad (now St Petersburg) in 1941-4 was undertaken. ${ }^{37}$ The results of this study show that there was no difference between the subjects exposed to starvation in utero and those starved during infant life in glucose tolerance, insulin concentrations, blood pressure, and lipid concentrations. However, concentrations of von Willebrand factor (a marker of endothelial cell dysfunction) were raised in those exposed to malnutrition in utero. Thus, intrauterine malnutrition as a result of maternal starvation was not associated with glucose intolerance, dyslipidaemia, hypertension, or cardiovascular disease, but was associated with a suggestion of endothelial cell dysfunction in adulthood.

The explanation for the apparent discrepancies between the Dutch hunger winter and the Leningrad famine studies are presently uncertain. In Holland, affected individuals were subjected to an acute period of famine followed by relatively good nourishment, whereas in Russia individuals were poorly nourished leading up to the famine. After a period of severe malnutrition, nourishment remained poor in Russia for a considerable period of time thereafter. Thus, to speculate, it is possible that differential nutritional stimuli, after a period of malnutrition, produce greatly different "catch up" growth. Differential nutrition would also affect maternal body composition, which might in turn influence fetal development. For example, a plentiful food supply would potentially 
produce overweight mothers who would be more insulin resistant that lean mothers. Maternal insulin resistance might then have an adverse influence on growth and development of the fetus during pregnancy.

A wide variety of factors, apart from maternal malnutrition during pregnancy, can also cause undernourishment in the human fetus. These include poor maternal nutritional reserves, inadequate uterine blood flow, or defective placental transfer of nutrients. As a consequence of the operation of one or more of these factors, the nutrient demand of the fetus might exceed the nutrient supply, with detrimental consequences for fetal growth and development.

To date, it is not clear how fetal undernutrition could result in adverse metabolic and physiological changes leading to adult disease. However, considerable evidence supports the notion that components of the diet are important regulators of gene expression and might therefore be important mediators of alterations in fetal growth and development. It has recently been shown that nutritional manipulation of the diet with fatty acids can have effects on activation of nuclear receptors that powerfully regulate gene expression. For example, certain fatty acids are ligand activators of nuclear protein peroxisomal proliferator activated receptors (PPARs). These nuclear receptors bind to a region within the promoter regions of genes involved in lipid metabolism and consequently are able to promote or repress the expression of many different genes. $^{38}$

In support of the notion that manipulation of the diet can powerfully modulate gene expression, we have shown that manipulation of the dietary carbohydrate to protein ratio alters fibrinogen gene expression using a reproducible reverse transcriptase polymerase chain reaction technique. In rats exposed to an isocaloric increase in the ratio of dietary carbohydrate to protein from weaning until adulthood, there was reduced expression of the three fibrinogen genes in rat liver and a parallel change in plasma fibrinogen concentration. ${ }^{39}$

Fetal exposure to maternal undernutrition might influence the growth and differentiation of tissues in the fetus. Recent experiments in a rat model of altered maternal nutrition show that a maternal low protein diet might permanently alter the function (and perhaps structure) of the developing fetal liver. The activities of glucokinase and glutamine synthase associated with the anabolic perivenous zone of the liver are reduced, whereas catabolic, periportally situated enzymes such as phosphoenolpyruvate carboxykinase and carbamyl phosphate synthetase are increased. Because hepatic glucose production is periportal, the liver might develop to favour production rather than the utilisation of glucose. ${ }^{40}$

We have shown that both left and right liver lobes might be differentially affected by maternal malnutrition. Using the same dietary manipulation in the pregnant rat dam as above, we showed that differentially reduced fibrinogen gene expression occurred in the left liver lobe compared with the right liver lobe. ${ }^{41} \mathrm{We}$ suggest that any effect of maternal nutritional stimuli on development of the fetal liver may also be modulated by the unique fetal liver blood supply. The fetal hepatic circulation is different from that of adults because of the presence of the ductus venosus, which closes shortly after birth in humans (and also in rats and sheep). Maternally derived nutrients reaching the fetal liver from the placenta are transported via the umbilical vein. The fetal left liver lobe receives a greater blood supply than the right lobe because a differential hepatic blood supply preferentially favours the left lobe. ${ }^{42}$

Thus, these data suggest that the left fetal liver lobe normally receives a greater stimulus to development, imparted by the received supply of maternal nutrients, growth factors, and hormones. We speculate from the combined data that the left hepatic lobe might be more vulnerable to any alteration of received maternal stimuli during development.

The synthesis of long lived proteins might also be altered by fetal undernutrition. It has been shown that low birth weight is linked with reduced elasticity of major arterial conduits. Impaired synthesis of elastin laid down in utero and during early infancy might predispose to adult disease because the half life of elastin is extraordinarily long. It is suggested that the half life may be 40 years and, therefore, it is not inconceivable that impaired production or increased degradation of elastin within the vasculature would predispose to less compliant arteries and hypertension. ${ }^{8}$

DOES A CHANGE IN EITHER HORMONAL AXES OR TISSUE RESPONSES TO SPECIFIC HORMONES LINK FETAL GROWTH WITH ADULT DISEASE?

The other type of mechanism by which reduced fetal growth could cause long term effects is by either altering the set point of hormonal axes that control growth and development or, alternatively, by changing the threshold response of the tissue to the hormonal stimulus. Although a considerable body of evidence has been produced to support the first of these suggestions, little if no published data exist investigating the second suggestion in humans.

Because the placenta is impermeable to many hormones, especially the polypeptide hormones and growth factors, the fetus and placenta form a substantially autonomous unit in endocrine terms. In response to undernutrition or other prenatal stressful stimuli, the fetus reduces insulin secretion and increases the concentrations of several hormones that modulate fetal and placental metabolism to increase fuel availability, redistribute blood flow, and alter the rate and pattern of fetal growth. Enhanced adrenal growth, together with raised cortisol values and an earlier prepartum rise in fetal plasma cortisol, are associated with increased concentrations of catecholamines and $\beta$-endorphins. The concentrations of other hormones or growth factors including thyroxine, insulin, and insulin-like growth factor I (IGF-I) might fall. ${ }^{43}$ Many of these hormones 
have well characterised programming or imprinting effects, which occur during specific developmental windows and persist throughout life. Recent experimental studies suggest that the hypothalamic-pituitary-adrenal axis (HPA) might play a particularly important role. Animal experiments have shown that adverse influences in prenatal or early postnatal life permanently alter the biological and behavioural responses in the adult offspring by means of long term changes in the set point of central and peripheral tissue sensitivity to glucocorticoid hormone. Exposure of pregnant rats to a variety of stressors, including low protein diets, alcohol, physical restraint, or nonabortive maternal infections, has shown that the offspring have increased HPA activity, with increased stress induced corticosteroid secretion in adult life. ${ }^{44-47}$ The effects of these stressors may be mediated by excessive fetal exposure to glucocorticoid hormone, resulting in persisting alterations in HPA activity. In support of this proposal, prenatal treatment of rats with dexamethasone or the use of carbenoxolone to inhibit placental and fetal $11 \beta$ hydroxysteroid dehydrogenase increase fetal glucocorticoid exposure, leading to permanently increased activity of the HPA, with increased circulating basal and stress induced secretion of corticosterone. ${ }^{48}{ }^{49}$ This is probably effected in part by lifelong alterations in the numbers of glucocorticoid receptors in the hippocampus, which is an important site of negative feedback of the axis. ${ }^{50}$ Because programmed increases in HPA activity in humans and consequent raised circulating cortisol concentrations could contribute to the pathogenesis of the metabolic syndrome and link the syndrome with low birth weight, we recently measured fasting cortisol concentrations in the 370 men who took part in the Hertfordshire study. Men who had low birth weight had high plasma cortisol concentrations, the concentrations falling progressively from $408 \mathrm{nmol} /$ litre among men who weighed $\leqslant 5.5 \mathrm{lb}$ at birth to $309 \mathrm{nmol} /$ litre among those who weighed $\geqslant 9.5 \mathrm{lb} .{ }^{51}$ Higher cortisol concentrations were related to higher systolic blood pressure and to higher fasting and two hour plasma glucose concentrations. We investigated a subset of the men and showed that those who were small at birth had increased adrenocortical responses to adrenocorticotrophin, suggesting that the increased cortisol secretion resulted from increased activity of the HPA. ${ }^{52}$ These preliminary findings suggest that intrauterine programming of the HPA might play an important part in mediating the association between low birth weight and reduced glucose tolerance in adult life.

\section{Conclusions}

There is now a considerable body of evidence to support an association between reduced birth weight and future adult type 2 diabetes, hypertension, and coronary artery disease in men. There is less information available for stroke and for women, and whether men and women have the same risk of developing these diseases on a background of altered fetal development is presently uncertain.

Few studies have access to other measurements of fetal growth apart from birth weight and, unfortunately, birth weight is only a crude proxy measure of fetal growth and development. More detailed information is needed to determine whether thinness or stunting are more informative parameters. To date, an explanation for the association between altered patterns of fetal growth and programmed development of adult disease remains elusive. The bulk of evidence suggests that the pathogenesis of atherosclerotic vascular disease and related disorders, such as the metabolic syndrome and/or type 2 diabetes, is influenced by factors occurring in utero. Animal evidence supports the notion that maternal nutrition might be able to programme adult metabolism, although whether altered maternal nutrition programmes diseases such as type 2 diabetes and atherosclerotic vascular disease is not known. At present, the available data do not support a detrimental role for a particular maternal nutritional excess or deficiency and more research is needed. We suggest that it is essential to investigate the impact of specific nutrients to modulate gene expression and then to study their potential to influence fetal growth and development.

An increasing body of evidence suggests that alterations in the set point of major hormonal axes controlling growth and development, particularly the HPA, may be an important mechanism linking fetal development to future adult disease. Although these early changes might determine susceptibility, additional factors such as obesity, ageing, and physical inactivity, that act to increase insulin resistance, must also play a part in determining the time, onset, and severity of disease.

We suggest that an understanding of the mechanisms regulating fetal development is important because an improved understanding of these mechanisms will emphasise new approaches to prevent diseases such as atherosclerotic vascular disease and type 2 diabetes. Assuming that fetal development can be better optimised, there is then the potential to reduce the escalating impact of type 2 diabetes and atherosclerotic vascular disease.

1 Barker DJ. Mothers, babies and health in later life. Edinburgh: Churchill Livingstone, 1998

2 Rich-Edwards JW, Stampfer MJ, Manson JE, et al. Birth weight and risk of cardiovascular disease in a cohort of women followed up since 1976. BMF 1997;315:396-400.

3 Stein CE, Fall CH, Kumaran K, et al. Fetal growth and coronary artery disease in South India. Lancet 1996;348: $1269-73$.

4 Leon DA, Koupilova I, Lithell HO, et al. Failure to realise growth potential in utero and adult obesity in relation to blood pressure in 50 year old Swedish men. BMF 1996;312:401-6.

5 Dunger DB, Ong KK, Huxtable SJ, et al. Association of the INS VNTR with size at birth. Nat Genet 1998;19:98-100.

6 Barker DJ, Winter PD, Osmond C, et al. Weight in infancy and death from ischaemic heart disease. Lancet 1989;ii: 577-80

7 Barker DJ, Godfrey KM, Osmond C, et al. The relation of fetal length, ponderal index, and head circumference to blood pressure and the risk of hypertension in adult life. Paediatr Perinat Epidemiol 1992;6:35-44.

8 Martyn CN, Barker DJP, Osmond C. Mother's pelvic size, fetal growth, and death from stroke and coronary artery disease in men in the UK. Lancet 1996;348:1264-8. 
9 Forsen T, Eriksson JG, Tuomilehto J, et al. Mother's weight in pregnancy and coronary heart disease in a cohort of

.

Frankel S, Elwood P, Sweetnam P, et al. Birthweight, adult risk factors and incident coronary artery disease: the Caerphilly study. Public Health 1996;110:139-43.

11 Hales CN, Barker DJ, Clark PM, et al. Fetal and infant growth and impaired glucose tolerance at age 64 . $B M f$ 1991;303:1019-22.

12 Phillips DIW. Birth weight and the future development of diabetes. A review of the evidence. Diabetes Care 1998; 21(suppl 2):B150-5.

13 Law CM, Shiell AW. Is blood pressure inversely related to birthweight? The strength of evidence from a systematic review of the literature. F Hypertens 1996;14:935-41.

14 Barker DJ, Hales CN, Fall CH, et al. Type 2 (non-insulin dependent) diabetes mellitus, hypertension and hyperlipidemia (syndrome X): relation to reduced fetal growth. Diabetologia 1993;36:62-7.

15 Phillips DI, Barker DJ, Hales CN, et al. Thinness at birth and insulin resistance in adult life. Diabetologia 1994;37: $150-4$.

16 McKeigue PM, Lithell H, Leon DA. Glucose tolerance and resistance to insulin-stimulated glucose uptake in men aged 70 years in relation to size at birth. Diabetologia $1998 ; 41$ 1133-8.

17 Flanagan DEH, Moore VM, Godsland IH, et al. Fetal growth and the physiological control of glucose tolerance in adults: an analysis using the minimal model. Am F Physio 2000;278:E700-6.

18 Hofman PL, Cutfield WS, Robinson EM, et al. Insulin resistance in short children with intrauterine growth retardation. I Clin Endocrinol Metab 1997;82:402-6.

19 Clausen JO, Borch-Johnsen K, Pedersen O. Relation between birthweight and the insulin sensitivity index in a population sample of 331 young healthy Caucasians. Am $\mathcal{F}$ Epidemiol 1996;146:23-31.

20 Phillips DIW. Insulin resistance as a programmed response to fetal undernutrition. Diabetologia 1996;39:1119-22.

21 Whincup PH, Cook DG, Adshead F, et al. Childhood size is more strongly related than size at birth to glucose and insulin levels in 10-11 year-old children. Diabetologia 1997;40 lin levels

22 Law CM, Gordon GS, Shiell AW, et al. Thinness at birth and glucose tolerance in seven-year-old children. Diabe Med 1995;12:24-9.

23 Yajnik CS, Fall $\mathrm{CH}$, Vaidya U, et al. Fetal growth and glucose and insulin metabolism in four-year-old Indian children. Diabetic Med 1995;12:330-6.

24 Forrester TE, Wilks RJ, Bennett FI, et al. Fetal growth and cardiovascular risk factors in Jamaican schoolchildren. BMF 1996;312:156-60.

25 Fowden AL. The role of insulin in prenatal growth. $\mathcal{F} \mathrm{Dev}$ Physiol 1989;12:173-82.

26 Hattersley AT, Beards F, Ballantyne E, et al. Mutations in the glucokinase gene of the fetus result in reduced birth weight. Nat Genet 1998;19:268-70.

27 Tamemoto H, Kadowaki T, Tobe K, et al. Insulin resistance and growth retardation in mice lacking insulin receptor and growth retardation in mice lackir

28 McCance DR, Pettitt DJ, Hanson RL, et al. Birth weight and non-insulin dependent diabetes: thrifty genotype, thrifty phenotype, or surviving small baby genotype? $B M \mathscr{F}$ 1994;308:942-5.

29 Ong KK, Phillips DI, Fall C, et al. The insulin gene VNTR, type 2 diabetes and birthweight. Nat Genet 1999;21:262-3.

0 Morton NE. The inheritance of human birth weight. Ann Hum Genet 1955;19:262-8.

31 Penrose LS. Some recent trends in human genetics. Caryologia 1954;6:521-9.

32 Snow MHL. Effects of genome on fetal size at birth. In: Sharp F, Fraser RB, Milner RDG, eds. Fetal growth. Proceedings of the 20th study group, RCOG. London: Royal College of Obstetricians and Gynaecologists, 1989:1-11.
33 Poulsen P, Vaag AA, Kyvik KO, et al. Low birthweight is associated with NIDDM in discordant monozygotic and dizygotic twin pairs. Diabetologia 1997;40:439-46.

34 Persson E, Jansson T. Low birth weight is associated with elevated adult blood pressure in the chronically catheterized guinea-pig. Acta Physiol Scand 1992;145:195-6.

35 Langley SC, Jackson AA. Increased systolic blood pressure in adult rats induced by fetal exposure to maternal low protein diets. Clin Sci (Colch) 1994;86:217-22.

36 Ravelli AC, van der Meulen JH, Michels RP, et al. Glucose tolerance in adults after prenatal exposure to famine. Lancet 1998:351:173-7.

37 Stanner SA, Bulmer K, Andres C, et al. Does malnutrition in utero determine diabetes and coronary heart disease in adulthood? Results from the Leningrad siege study, a cross sectional study. BMF 1997;315:1342-8.

38 Fruchart J-C, Duriez P, Staels B. Peroxisome proliferatoractivated receptor-alpha activators regulate genes governatherosclerosis. Curr Opin Lipidol 1999;10:245-57.

39 Zhang J, Desai M, Ozanne SE, et al. Two variants of quantitative reverse transcriptase PCR used to show differential expression of fibrinogen genes in rat liver lobes. Biochem $\mathcal{F}$ 1997;321:769-75.

40 Burns SP, Desai M, Cohen RD, et al. Gluconeogenesis, glucose handling, and structural changes in livers of the adult offspring of rats partially deprived of protein during pregnancy and lactation. $\mathcal{F}$ Clin Invest 1997;100:1768-74.

41 Zhang J, Byrne CD. Differential hepatic lobar gene expression in offspring exposed to altered maternal dietary protein intake. Am f Physiol 2000;278:G128-36.

42 Edelstone DI, Rudolph AM, Heymann MA. Liver and ductus venosus blood flows in fetal lambs in utero. Circ Res $1978 ; 42: 426-33$.

43 Owens JA, Owens PC, Robinson JS. Experimental fetal growth retardation: metabolic and endocrine aspects. In: Gluckman PD, Johnston BM, Nathanielsz PW, eds. Advances in fetal physiology. New York: Ithaca, 1989:263-

44 Barbazanges A, Piazza PV, Le Moal M, et al. Maternal glucocorticoid secretion mediates long-term effects of prenatal stress. F Neurosci 1996;16:3943-9.

45 Reul JM, Stec I, Wiegers GJ, et al. Prenatal immune challenge alters the hypothalamic-pituitary-adrenocortical axis in adult rats. $\mathcal{F}$ Clin Invest 1994;93:2600-7.

46 Lee S, Imaki T, Vale W, et al. Effect of prenatal exposure to ethanol on the activity of the hypothalamic-pituitaryadrenal axis' activity of the offspring: importance of the time of exposure to ethanol and possible modulating mechanisms. Mol Cell Neurosci 1990;1:168-77.

47 Langley-Evans SC. Intrauterine programming of hypertension by glucocorticoids. Life Sci 1997;60:1213-21.

48 Lindsay RS, Lindsay RM, Edwards CR, et al. Inhibition of $11 \beta$ hydroxysteroid dehydrogenase in pregnant rats and the programming of blood pressure in the offspring. Hypertension 1996;27:1200-4.

49 Benediktsson R, Lindsay RS, Noble J, et al. Glucocorticoid exposure in utero: new model for adult hypertension. Lancet 1993;341:339-41.

50 Levitt NS, Lindsay RS, Holmes MC, et al. Dexamethasone in the last week of pregnancy attenuates hippocampal glucocorticoid receptor gene expression and elevates blood pressure in the adult offspring of rats. Neuroendocrinology 1996;64:412-18.

51 Phillips DI, Barker DJ, Fall CH, et al. Elevated plasma cortisol concentrations; a link between low birthweight and the insulin resistance syndrome? F Clin Endocrinol Metab 1998; 83:757-60.

52 Reynolds RM, Bendall HE, Walker BR, et al. Hyperactivity of the hypothalamic-pituitary-adrenal axis may mediate the link between impaired fetal growth and the insulin resistance syndrome. F Endocrinol 1998;59:OC5. 